\title{
REPOUSO E MOVIMENTO: QUE TIPO DE ATRITO? O QUE RELATAM OS LIVROS DA 8 a SÉRIE DO ENSINO FUNDAMENTAL E DO ENSINO MÉDIO
}

\author{
Helena Caldas ${ }^{* 1}$, Altair L. Cunha ** \& Maria Elisa Magalhães \\ Departamento de Física - Centro de Ciências Exatas* \\ Universidade Federal do Espírito Santo (UFES) - Campus de Goiabeiras \\ Escola de $1^{\circ}$ e $2^{\circ}$ Grau "João Bley"**
}

\section{REST AND MOTION: WHAT KIND OF FRICTION? WHAT THE HIGH SCHOOL BOOKS TELL.}

\begin{abstract}
Resumo
Dados os resultados de diversos estudos sobre as dificuldades e as concepções de senso comum de estudantes e professores acerca do fenômeno do atrito sólido seco, o presente trabalho busca conhecer qual a associação promovida pelos livros da $8^{\text {a }}$ série do Ensino Fundamental e do Ensino Médio entre atrito sólido e movimento. O objetivo é verificar a contribuição dada por estes livros ao modelo "estudantil" sobre o atrito e, simultaneamente, mostrar aspectos que devem ser levados em conta quando se estuda este fenômeno. As análises indicam que a abordagem escolhida pelos livros onde se inicia o estudo do atrito não favorece a formação conceitual adequada sobre o fenômeno na população alvo dos livros.
\end{abstract}

\section{Summary}

According to the results of several studies about students and teachers difficulties and common sense conceptions concerning the phenomenon of dry solid friction, the present work intends to find which is the association between solid friction and motion promoted by high school books. The goal is to verify the contribution given by these books to the student friction model and, simultaneously, to show aspects that should be taken into account when this phenomenon is studied. The analyses indicate that the approach chosen by the books to initiate the study of friction does not collaborate to the adequate conceptual formation about the phenomenon on the books target population.

\section{Introdução}


Diversos trabalhos sobre análise de conteúdo de livros didáticos, embora utilizando diferentes metodologias ou perseguindo diferentes objetivos, mostram direta ou indiretamente a importância destes no cotidiano da prática de ensino (Aguirre de Cárcer I., 1993; Brincones I. \& Otero J., 1994; Caldas H., 1999; Caldas H. \& Saltiel E., 1999b; Cunha A. L. \& Caldas H., 2000; Islas S. M. \& Guridi V. M., 1999).

As diferentes investigações indicam que o professor funciona como um elo de ligação entre os alunos e os textos didáticos e, a partir destes, prepara as suas aulas, escolhe as questões a discutir e monta as suas atividades em sala de aula.

Assim, parece indiscutível a relevância do papel desempenhado pelos livros didáticos no processo de aquisição do conhecimento e de como estes podem contribuir, positiva ou negativamente, para a formação ou permanência das chamadas concepções de senso comum e dos modos de raciocínio de estudantes e professores.

Por outro lado, os resultados de vários trabalhos sobre concepções e modos de raciocínio de senso comum acerca do fenômeno do atrito sólido seco, desenvolvidos com estudantes de várias culturas e de diversos níveis de ensino, (Besson U., 1997; Caldas H., 1999; Caldas H. \& Magalhães M. E., 1999; Caldas H. \& Saltiel E., 2000; Caldas H. \& Saltiel E., 1995; Shaw D.E., 1979; Wehrbein, 1992), assinalam uma série de dificuldades com que os estudantes se confrontam no estudo deste fenômeno.

Destas dificuldades, destacamos aqui aquelas que envolvem a relação estreita existente entre os movimentos dos sólidos e a definição ou caracterização dos tipos de atrito aos quais estes movimentos são associados.

O problema reside essencialmente no fato de que o atrito estático nem sempre está associado a todas as situações de repouso num dado referencial e nem todas as situações de movimento estão associadas ao atrito cinético, como é o caso, por exemplo, do movimento de rolamento sem escorregamento. Isto ocorre, pois o atrito está associado ao movimento ou ao eventual movimento de escorregamento relativo das superfícies em contato, umas em relação às outras, e não ao "movimento", tendência de "movimento" ou "repouso" dos sólidos num dado referencial.

Esta questão pode ser exemplificada por intermédio dos resultados de um estudo exploratório desenvolvido com 53 professores de Física da $8^{\underline{a}}$ série do Ensino Fundamental e do Ensino Médio de Vitória e de Cachoeiro de Itapemirim (ES), que faziam um curso de atualização para professores ${ }^{1}$, ministrado por professores do Departamento de Física da Universidade Federal do Espírito Santo. Este estudo (Caldas H. \& Magalhães M. E., 1999) mostrou que a maioria da população interrogada tem tendência a associar o atrito estático somente a situações de repouso e, consequentemente, o atrito cinético é associado a situações, quaisquer que elas sejam, onde exista movimento.

Assim, foi proposta a estes professores uma situação simples e sem ambigüidades, onde uma esfera indeformável rolava sem escorregar sobre um plano inclinado. Os resultados gerais da pesquisa foram os seguintes:

- Um pouco menos de um terço dos professores $(32,1 \%)$ considerou o atrito entre a esfera e o plano como sendo estático (resposta correta), mas apenas $15,1 \%$

\footnotetext{
${ }^{1}$ Curso financiado pela CAPES (1999).
} 
justificou corretamente a sua resposta (o atrito é estático porque a esfera rola mas não desliza). Os restantes apresentaram justificativas em termos da magnitude da área de contato, o que não sustentava as suas respostas.

- $30,2 \%$ considerou que o atrito era cinético porque a esfera estava em movimento sobre o plano.

- $15,1 \%$ considerou que existia um atrito de rolamento porque a esfera rolava sobre o plano, mas para os professores esta classificação não tinha relação alguma com a deformação ou não dos sólidos.

- 5,6\% considerou que o atrito era desprezível porque a área de contato era muito pequena, não sendo suficiente para "dificultar" ou "prender" o movimento.

- $17 \%$ preferiram não responder pois, em geral, não tinham clareza sobre o atrito existente neste tipo de movimento.

Desta forma, o conjunto dos resultados deste estudo exploratório, do qual o presente trabalho diretamente se origina, aliado aos resultados obtidos com estudantes de várias culturas nos trabalhos anteriormente citados, que já sinalizavam, entre outros, este tipo de dificuldades que o estudo do atrito produz em alunos de diversos níveis de ensino, nos dão elementos suficientes para procurar saber, dada a importância dos livros didáticos no processo do ensinar e do aprender, se estes reforçam ou não as tendências apontadas pelas pesquisas no que se refere à problemática geral que o próprio título do presente artigo resume (Repouso e Movimento: que tipo de atrito?).

Portanto, o presente trabalho centra-se na relação que os livros da $8^{\underline{a}}$ série do Ensino Fundamental e aqueles do Ensino Médio promovem entre o atrito sólido seco e os movimentos aos quais este fenômeno é associado, com o objetivo de verificar a contribuição dada por estes livros ao modelo "estudantil" sobre o fenômeno em questão.

\section{Objeto de análise}

No que diz respeito aos livros da $8^{\underline{a}}$ série, escolheu-se como objeto de análise os livros indicados pelo MEC no Guia do Livro Didático de $1999^{2}$, pois verificou-se que as escolas brasileiras de Ensino Fundamental seguem, em geral, as diretrizes do MEC, adotando como livros-texto aqueles escolhidos por este Ministério.

Constatou-se que o livro $L_{9}$ não é adotado por nenhuma escola do Estado do Espírito Santo e nem é comercializado pelas principais livrarias da capital do Estado. Por este motivo, não se constituiu em objeto de interesse das nossas análises, dada a estreita relação entre este estudo e aquele realizado com professores do Espírito Santo, já anteriormente citado. Por outro lado, o livro $L_{8}$ também não é adotado, sendo substituído nas escolas, pelo livro $L_{7}$ dos mesmos autores. Assim, entre os dois, foi este último que se constituiu em objeto de análise.

\footnotetext{
${ }^{2}$ Referências Bibliográficas em Anexos, denominadas e numeradas de $\mathrm{L}_{1}$ a $\mathrm{L}_{9}$.
} 
No que diz respeito aos livros do Ensino Médio, escolheu-se como objeto de análise aqueles que freqüentemente eram utilizados nas escolas de Vitória - ES ${ }^{3}$.

Para satisfazer este critério, foram consultadas várias escolas escolhidas aleatoriamente, incluindo escolas públicas e particulares, onde se colhia a informação sobre o livro didático por elas adotado. Verificamos que, em geral, não existia uma grande dispersão nos livros adotados pelas escolas consultadas, o que facilitou a decisão da escolha dos livros a analisar.

Por outro lado, verificamos também se tal escolha era compatível com a variedade dos livros disponíveis no mercado das principais livrarias que se dedicam à comercialização de livros didáticos.

O cruzamento destes dois tipos de informação permitiu-nos, então, chegar a uma lista de livros que garantia o critério escolhido.

A esta lista pareceu-nos interessante acrescentar a apostila utilizada pelas escolas do grupo "Objetivo", como representante importante em Vitória (e, também, em outros estados brasileiros) das escolas que utilizam material didático próprio, podendo este ser também disponibilizado para outras escolas, conforme fomos informados.

\section{Metodologia}

Os livros foram então analisados seguindo uma metodologia já testada e utilizada em outros trabalhos (Caldas H., 1994; Caldas H. \& Saltiel E., 1999b; Cunha A. L. \& Caldas H., 2000):

“... a partir do conhecimento do modelo "estudantil" sobre um dado fenômeno, modelo este que não corresponde ao modelo físico cientificamente aceito, procurase verificar se o conteúdo apresentado ao aprendiz, permite ou não que o seu modelo sobre o fenômeno em estudo seja colocado em questão ou se, ao contrário, até contribui para reforçá-lo: é uma metodologia que tem como base as dificuldades e o ponto de vista "daquele que aprende" e não, o ponto de vista "daquele que já sabe”." (Cunha A. L. \& Caldas H., 2000)

Desta forma, esta perspectiva de análise crítica de livros parte de elementos de análise definidos exclusivamente em função das principais tendências das dificuldades, concepções e modos de raciocínio de senso comum ou dos modelos dos aprendizes sobre determinado conteúdo, neste caso, da física, conhecendo-se os pontos precisos a serem estudados, isto é, conhecendo-se exatamente o que se procura e porque se procura.

O corpo a analisar é, assim, recortado nos diferentes elementos de análise, que podemos definir como "entradas" e que constituem a indicação dos aspectos gerais a analisar. Em cada uma destas "entradas" são definidos os aspectos específicos a observar, o que pode levar à formação de diferentes categorias, categorias estas determinadas pela diversidade das

\footnotetext{
${ }^{3}$ Referências Bibliográficas em Anexos, denominadas e numeradas de $\mathrm{S}_{1}$ a $\mathrm{S}_{8}$.
} 
abordagens nos livros didáticos no que se refere, particularmente, ao elemento do conteúdo em processo de análise.

Portanto, tendo sistematicamente como pano de fundo as tendências do conhecimento comum do aprendiz reveladas por resultados de investigação da área de pesquisa em Ensino (no presente caso, Ensino de Física) no tema escolhido para estudo, ao "fazer" analítico interessa não só, as formas de expressão conteúdo, mas também como esse conteúdo é articulado.

No presente trabalho, o corpo a analisar trata, então, dos itens do conteúdo que se referem ao fenômeno do atrito sólido (entre sólidos) seco (sem adição de fluido) nos livros da $8^{a}$ série do Ensino Fundamental e naqueles do Ensino Médio.

Determinado pelos resultados de pesquisa atrás relatados (item II), o corpo objeto de análise foi recortado em um único elemento geral de análise (a "entrada"), definido como "Tipos de Atrito", procurando observar os aspectos que respondam às seguintes questões de estudo:

Do ponto de vista da Física

- Os livros fazem distinção entre atrito estático e cinético? Como estes fenômenos são distinguidos/definidos? A que movimentos são eles associados?

- O Atrito de rolamento é abordado nos livros? Como ele é definido? A que tipo de movimento é ele associado? Como este tipo de atrito se integra/relaciona com o atrito estático ou cinético?

Do ponto de vista da pesquisa em Ensino de Física

- Em que medida os livros permitem ou não que o aprendiz associe o atrito cinético e o atrito estático, respectivamente, ao deslizamento e ao não deslizamento relativo do ponto, linha ou superfícies em contato?

\section{Algumas considerações sobre o atrito sólido seco}

Vamos aqui tecer algumas considerações sobre o fenômeno do atrito sólido seco, enfatizando as relações entre este fenômeno e o movimento dos sólidos, tendo em vista a temática física deste trabalho.

As leis do atrito sólido seco que nós conhecemos hoje, não são mais que as "leis de Coulomb" (nome este muito pouco utilizado no Brasil), que resumem as investigações de da Vinci (1452-1519) a Coulomb (1736-1806) sobre as interações de sólidos em contato, nos quais as superfícies são secas, isto é, sem nenhuma adição de fluido.

Convém lembrar o caráter empírico destas leis e o aspecto fenomenológico do estudo do fenômeno do atrito que abordaremos apenas sob o ponto de vista macroscópico.

Assim, na presença de um atrito sólido seco, as ações de contato entre dois sólidos são definidas pela resultante $(\mathbf{R})^{4}$ das forças de contato que cada uma das superfícies de contato exerce sobre a outra. Cada resultante, inclinada de um certo ângulo em relação à normal às superfícies em contato, é sempre dirigida para o interior de cada sólido (senão os sólidos "afundariam" uns nos outros) e admite duas componentes: uma, normal às superfícies de

\footnotetext{
${ }^{4}$ As grandezas vetoriais serão sempre representadas por símbolos em negrito.
} 
contato e a outra, tangencial a estas mesmas superfícies.

As componentes tangenciais $(\mathbf{T})$ das resultantes das ações das forças de contato $(\mathbf{R})$ que as superfícies dos sólidos em contato exercem umas sobre as outras, são o que chamamos de forças de atrito.

O fenômeno do atrito sólido seco, é assim representado (modelado) pela resultante das forças de contato que é exercida sobre cada uma das superfícies em contato e as suas leis serão determinadas pelas propriedades das componentes $\mathbf{T}$ e $\mathbf{N}$.

Este fenômeno só se manifesta se uma força exterior (ou um torque externo) for exercida sobre o sistema físico considerado. Se esta condição não for satisfeita, não podemos formalmente falar de atrito, pois as resultantes das ações de contato serão então normais a cada superfície de contato e as componentes tangenciais desta resultante, sobre cada uma das superfícies, serão assim, nulas.

Supondo que os sólidos em contato são indeformáveis, o fenômeno do atrito compreende, na realidade, dois fenômenos distintos: o atrito de não escorregamento ou de não deslizamento, conhecido como atrito estático e o atrito de escorregamento ou de deslizamento, conhecido como atrito cinético ou dinâmico.

A distinção clara entre estes dois tipos de atrito se faz necessária e importante, pois sendo cada um destes fenômenos regidos por leis diferentes, as propriedades das forças correspondentes são necessariamente diferentes ${ }^{5}$.

Em presença de um atrito estático as superfícies em contato estão, umas em relação às outras, em repouso relativo do ponto de vista do não escorregamento, isto é, podemos definir no contato (que pode ser um ponto, linha ou superfície plana) uma velocidade relativa de escorregamento nula, para cada superfície em contato, deslizando uma em relação à outra; em presença de um atrito cinético as superfícies em contato estão, umas em relação às outras, em movimento de escorregamento relativo não nulo, isto é, podemos definir no contato uma velocidade relativa de escorregamento não nula (Caldas H. \& Saltiel E., 1999a).

Desta forma, o atrito estático não ocorre somente quando os sólidos, solicitados por algum agente externo, permanecem em repouso num dado referencial e nem sempre que estes estão em movimento em relação a um determinado referencial, estamos em presença de um atrito cinético. É o caso de situações físicas onde um sólido tem um movimento não nulo (de rotação ou de translação) num dado referencial, com uma velocidade relativa de escorregamento no contato nula: caso do rolamento sem escorregamento ou de, por exemplo, do movimento de translação de dois blocos solidários, colocados um em cima do outro, deslizando sobre uma superfície horizontal.

No exemplo dos blocos solidários, o bloco que está "em cima" está em repouso em relação ao bloco "debaixo" e em movimento de translação em relação à superfície horizontal sobre a qual o conjunto desliza.

No caso do movimento de rolamento sem escorregamento, considerando o exemplo de uma esfera animada com este tipo de movimento sobre uma superfície qualquer (horizontal ou

\footnotetext{
${ }^{5}$ Não cabe, no escopo deste trabalho, expor estas diferenças. Consultar Caldas H.,1999 e Caldas H. \& Saltiel E., 1999a.
} 
inclinada), existe somente um ponto que a cada instante, à medida em que a esfera rola, está em contato com a superfície.

Se o movimento é sem deslizamento, o ponto de contato da esfera sobre a superfície sobre a qual ela rola não deslizará, isto é, a esfera não "patina" e, consequentemente, a velocidade relativa de escorregamento deste ponto em relação à superfície é nula: o atrito entre o sólido e a superfície de apoio, se ele existe, só pode ser estático, apesar do centro de massa da esfera não estar em repouso: ele translada-se na medida em que a esfera rola.

Por outro lado, um corpo que rola pode também escorregar e, nesse caso, a velocidade relativa de escorregamento do ponto de contato da esfera com a superfície de apoio seria diferente de zero: o atrito não seria mais estático, mas cinético.

Obviamente que a suposição genérica da perfeição geométrica e da rigidez absoluta das superfícies em contato é uma idealização da realidade. Na verdade, existe sempre uma deformação dos sólidos em contato, por menor que ela seja. O contato dá-se então segundo uma área, tanto menor quanto mais "duras" forem as superfícies em contato.

Considerando ainda uma esfera rolando sem deslizar sobre uma superfície horizontal, o contato não seria mais pontual, mas segundo uma área, devido à deformação. Tal fato, leva ao deslocamento do ponto de aplicação da resultante das forças de contato de um determinado comprimento $\lambda$, em relação ao único ponto de contato que existiria se não houvesse deformação.

Assim, nestas condições, o atrito manifestar-se-ia por um torque, devido ao deslocamento $\lambda$; este torque é normalmente chamado de momento de resistência ao rolamento e caraterizaria o fenômeno do atrito no rolamento, quando se considera a deformação dos sólidos, sendo $\lambda$ chamado de coeficiente de resistência ao rolamento e expresso em unidades de comprimento. Quanto menor é a deformação, menor é $\lambda$ e, portanto, menor é o momento de resistência ao rolamento.

Se os materiais em contato são suficientemente "duros" e a pressão de contato é baixa, o coeficiente $\lambda$ é ínfimo, podendo ser desprezado. A idealização dos contatos permite, portanto, uma boa aproximação na maioria dos fenômenos observados.

Entretanto, é preciso considerar que somente admitindo a deformação dos sólidos em contato e, portanto, a existência de um momento de resistência ao rolamento, é que é possível explicar como é que os sólidos que rolam sem escorregar atingem o repouso, além da contribuição dada pela resistência do ar: é na deformação dos sólidos que a energia é gasta, pois quando o atrito é estático não existe dissipação de energia.

Em resumo, os aspectos que envolvem a relação tipos de atrito/movimento, requerem de um lado, que se definam os limites em que podemos falar deste ou daquele tipo de atrito (caso do atrito de rolamento) e, de outro lado requerem, sem concessões, que se explicite claramente o referencial em relação ao qual o movimento está sendo definido (velocidades relativas de escorregamento). Qualquer tentativa de se ignorarem estes aspectos leva, no mínimo, a "confusões" ou considerações inadequadas.

Analisemos, então, o que relatam os livros a que se referem este trabalho. 


\section{Análise dos livros}

\section{V.1. $8^{\mathrm{a}}$ série do Ensino Fundamental}

Constatamos, de início, que a quase unanimidade dos livros, quando introduz o conceito de atrito, não faz uma distinção clara entre o atrito sólido seco, daquele com adição de fluido ou da resistência do ar, quando sabemos que as propriedades que regem estes dois últimos são bastante distintas daquelas do atrito sólido seco.

Quanto ao atrito sólido seco, embora não fique claramente definido que se trata especificamente deste tipo de atrito, podemos dividir os livros analisados em duas categorias gerais: categoria $c_{1}$ e categoria $c_{2}$ que se caracterizam, respectivamente, pela distinção ou não distinção entre atrito estático e cinético.

- Categoria $\mathbf{c}_{1}$ : Apenas um livro pode ser incluído na categoria $c_{1}$, pois distingue 0 atrito estático do cinético. Constata-se, entretanto, o aparecimento de um outro tipo de atrito, o atrito de rolamento, como mostra a citação ( $\mathrm{L}_{2}$, p.162):

"A força de atrito é denominada de atrito de deslizamento quando um corpo desliza pela superfície do outro; é denominada de atrito de rolamento quando um corpo não desliza, mas rola sobre o outro."

"Fala-se em atrito estático quando os corpos sólidos que se encontram em contato estão em repouso." 6

- Categoria $\mathbf{c}_{2}$ : Nesta categoria estão incluídos os 6 livros restantes, pois não distinguem os fenômenos em questão. Esta categoria pode ainda ser dividida em 3 subcategorias:

$\mathbf{c}_{2 a}$ : Pertencem a esta subcategoria os livros $\left(L_{1}, L_{4}\right.$ e $\left.L_{6}\right)$ que, não distinguindo o atrito estático do cinético, engloba-os num único fenômeno, o do "atrito", reinando a ambigüidade. Este amalgama se observa ao longo de todo o discurso dos textos e nas ilustrações (exemplos, figuras ou fotografias) que o suportam. Por exemplo, no livro $L_{1}$, podemos ler:

"Um corpo pode, ao se deslocar, manter a sua superfície em contato com a de outro corpo. A fricção que se estabelece entre os dois corpos recebe o nome de atrito (em negrito no original). Na verdade, cria-se uma força que representa uma resistência ao movimento do corpo, a força de atrito (em negrito no original). Esta força possui sempre sentido contrário à tendência do movimento" ${ }^{7}$

\footnotetext{
${ }^{6}$ Atrito de deslizamento, atrito de rolamento e atrito estático estão em itálico no texto original.

${ }^{7}$ Embora se defina inadequadamente o sentido da força de atrito, este aspecto não se constitui em elemento de análise no presente estudo. Para isso, consultar Caldas H. \& Saltiel E., 1999a e Cunha A. L. \& Caldas H., 2000.
} 
$\mathbf{c}_{2 \mathbf{b}}$ : Pertencem a esta subcategoria os livros $\left(\mathrm{L}_{3}, \mathrm{~L}_{5}\right)$ que, não distinguindo o atrito estático do cinético, definem apenas o atrito de deslizamento, ignorando o atrito estático. Entretanto, estes livros fazem a distinção, como na categoria $c_{1}$, entre atrito de deslizamento e atrito de rolamento, como podemos ver no exemplo $\left(L_{3}\right.$, p.140):

"Podemos identificar dois tipos de atrito com base no deslocamento de uma superfície sobre outra:

- atrito de deslizamento - quando uma superfície desliza sobre a outra;

> atrito de rolamento - quando uma superfície rola sobre a outra."

$\mathbf{c}_{2 \mathbf{c}}$ : Pertence a esta subcategoria o livro restante $\left(L_{7}\right)$ e podemos considerá-la uma subcategoria intermediária entre as duas anteriores, pois embora não se defina ou se nomeie claramente nenhum tipo de atrito, aborda-se, embora ambiguamente, a diferença entre 0 atrito "por arrastamento" e o atrito "por rolamento".

Como mostra a citação, referindo-se a duas figuras, uma onde se puxa um bloco sobre uma superfície e, outra, onde se puxa o mesmo bloco apoiado em dois lápis, o autor coloca :

"Para arrastar o bloco, é preciso fazer uma força para vencer o atrito."

"Apoiando o bloco em dois lápis. É mais fácil arrastá-lo, pois o atrito por rolamento é menor."

\section{Comentários e Discussão}

- Observa-se de imediato na citação do único livro da primeira categoria, uma confusão entre o fenômeno do atrito e a força de atrito que representa a manifestação do fenômeno: "A força de atrito é denominada de atrito de deslizamento...; é denominada de atrito de rolamento...".

Nos outros livros analisados encontra-se também, por diversas vezes ao longo dos textos, este tipo de afirmativas ou afirmativas similares, menos ambíguas, tais como: "o atrito é uma força...”, “...essa força chama-se atrito”, “o atrito empurra...”, “...a força de atrito existente entre...".

Ora o atrito, evento que ocorre entre as superfícies de contato dos sólidos quando uma força externa ao sistema é sobre eles exercida, é representado (modelado) pela resultante das forças de contato tangenciais, a força de atrito, exercida sobre cada um dos sólidos em contato e obedecendo à $3^{\text {a }}$ lei de Newton.

Portanto, a força de atrito não existe entre as superfícies, ela é exercida em cada uma das superfícies em contato e o que ocorre ("existe") entre as superfícies em contato, é o evento ou o fenômeno que chamamos de atrito. Do mesmo modo, o atrito não pode empurrar um objeto, pois esta ação implica na existência de uma força sendo exercida sobre este objeto.

Esta "confusão" não é desejável, embora possa ser observada em livros de todos os níveis de ensino, pois favorece a idéia de que a UM fenômeno de atrito corresponde UMA única força de atrito, contribuindo assim para reforçar a grande tendência dos estudantes em representar o atrito existente entre dois sólidos em contato por uma única força, ignorando a existência da $3^{\underline{a}}$ lei de Newton, conforme observado por Caldas H. \& Saltiel E. (1995). 
Reportando-nos ao contexto mais geral da Dinâmica, tal tipo de "confusão" só contribui para favorecer o esvaziamento da importante questão "o que é que age sobre o que" (Viennot L., 1979), fonte de inesgotáveis dificuldades dos aprendizes (Meningaux J., 1986; Viennot L., 1996).

- Verifica-se ainda nesta categoria $\left(c_{1}\right)$, que se o atrito de deslizamento é corretamente definido, a definição de atrito estático é equivocada, confirmando ou favorecendo, de um lado, a associação entre repouso dos corpos e atrito estático e, de outro lado, a idéia de que basta os corpos em contato estarem em repouso para que exista atrito (estático).

Ora, já vimos que este atrito só passa a existir entre as superfícies de contato dos sólidos, a partir do momento em que uma força externa ao sistema sólido-sólido seja nele exercida. Caso contrário, o fenômeno do atrito simplesmente não existe!

Vimos, também, que um corpo pode estar em movimento num dado referencial e existir a presença de um atrito estático.

- Observando de outro ponto de vista, à caracterização dos tipos de atrito sólido é ainda acrescentado nesta categoria $\left(c_{1}\right)$ e compartilhado por metade dos livros da categoria $c_{2}$, outro tipo de atrito, o atrito de rolamento que apareceria quando um corpo rola sobre o outro.

O aparecimento deste atrito de rolamento é no mínimo estranha, pois como em geral consideramos implicitamente a perfeição geométrica dos sólidos em contato e a sua rigidez absoluta (sólidos indeformáveis), o contato entre o sólido que rola e a superfície de apoio será feito segundo um ponto (contato pontual, como no caso da esfera) ou segundo uma linha (contato linear, como no caso do cilindro) e, neste caso, como discutido anteriormente, este tipo de atrito não existe.

Desta forma, se os autores dos livros no nível de ensino da $8^{a}$ série optarem por tratar do atrito de rolamento, então devem abordar este assunto sem ambigüidades e sem dar margem a equívocos, delineando as condições em que este tipo de atrito aparece e porque aparece. Porém isto não é trivial. Note-se que mesmo nos livros universitários de Física Básica ${ }^{8}$, em geral, este fenômeno não é estudado, pois os sólidos são considerados, implícita ou explicitamente, indeformáveis. Nesses casos, se um sólido rola e se existe atrito entre as superfícies de contato, ele será estático se não houver deslizamento relativo das superfícies em contato e cinético, caso contrário.

- Verifica-se, de forma geral, permeado nos textos de todos os livros e muitas vezes em definições colocadas em destaque, que a questão de referenciais está ausente do discurso. Assim, os movimentos (por vezes, deslocamentos) aos quais o atrito é associado são tomados em termos "absolutos": ele se opõe ao "movimento de um corpo" ou ele é resistente "ao movimento". Que movimento? Movimento em relação a que?

Já vimos que o que intervém no estudo do atrito é o movimento de escorregamento

\footnotetext{
${ }^{8}$ Destacamos autores habitualmente utilizados (como livro texto ou de consulta) no Ensino Superior Brasileiro (Caldas H. \& Saltiel E., 1999b): Halliday \& Resnick, Alonso \& Finn, McKelvey \& Grotch, Tipler, Eiseberg \& Lerner, Sears \& Zemansky, Nussenzveig.
} 
relativo das zonas de contato dos sólidos concernentes, umas em relação às outras (atrito cinético) ou a ausência deste movimento (atrito estático) e não os movimentos "dados" num determinado referencial.

Este "esquecimento", além de não ser adequado do ponto de vista científico, induz ou facilita uma formação conceitual equivocada sobre o fenômeno em questão.

Por outro lado, já em 1978, Saltiel (1978) mostrou como é difícil para os estudantes raciocinar em termos de referenciais e neles definir as grandezas físicas. Para eles, os movimentos dos objetos são definidos de maneira intrínseca, a partir das suas causas dinâmicas:

"O estudante quase nunca se pergunta sobre a questão do referencial pois ele não vê necessidade... as velocidades, assim como as forças, existem por elas mesmas, independentemente dos referenciais, e servem para explicar o movimento... $O$ movimento (próprio) e a imobilidade são definidos intrinsecamente e não como um deslocamento em relação a ..." (Saltiel \& Malgrange, 1979)

Desta forma, as opções dos autores dos livros, talvez na tentativa de simplificar a problemática envolvida no estudo do atrito, evitando a questão dos referenciais, compactuam com as reconhecidas dificuldades dos aprendizes nesta área e, no mínimo, não contribuem para que estas sejam problematizadas.

Reforçando esta questão, todos os exemplos, diagramas, figuras e ilustrações que acompanham a exposição teórica se referem somente ao caso particular de objetos deslocando-se sobre superfícies fixas, sem que esta opção ou limitação do estudo seja sublinhada. Neste caso, o movimento de escorregamento relativo do objeto em relação à superfície confunde-se com o "movimento" deste no referencial da superfície. Este fato corrobora, de um lado, com a concepção de que os objetos possuem movimentos "intrínsecos" e, de outro lado, não permite distinguir o movimento destes, num dado referencial, do movimento de escorregamento relativo das superfícies que intervém no fenômeno do atrito.

Em termos objetivos, a análise dos livros da $8^{a}$ série mostrou, em resumo, que:

- No caso em que é definido (apenas um livro), o atrito estático é associado inequivocamente ao "repouso" dos corpos num dado referencial.

- O atrito estático não é definido no restante dos livros analisados (6 livros) e, portanto, não é distinguido do atrito cinético.

- Nos casos em que é definido (4 livros), o atrito cinético é associado ao "movimento" de translação dos corpos num dado referencial e o atrito de rolamento ao movimento de rotação.

- Em 4 livros o tema do atrito é abordado de modo geral, associando indiscriminadamente os movimentos de translação e rotação à presença de um "atrito". 
- Nos casos em que é objetivamente definido (3 livros), o atrito de rolamento é abordado de forma inadequada.

\section{V.2. Ensino Médio}

Nos livros do Ensino Médio existe uma unanimidade no tratamento dado ao tema do atrito sólido seco: todos eles definem e distinguem claramente o atrito estático do atrito cinético, apoiando geralmente as suas exposições no exemplo de um objeto que, em repouso sobre uma superfície horizontal, é solicitado a deslocar-se quando uma força horizontal constante é nele exercida.

Esta forma de apresentar o fenômeno do atrito leva invariavelmente à associação explícita do atrito estático a situações de repouso e iminência de movimento de translação no referencial dado e do atrito cinético a situações de movimento de translação nesse referencial.

De fato, a maioria dos livros sequer menciona que o atrito ou as forças de atrito relacionam-se com o movimento de escorregamento relativo das superfícies em contato. Apenas 3 livros $\left(S_{1}, S_{2}\right.$ e $\left.S_{5}\right)$ mencionam eventualmente este aspecto, de forma mais ou menos clara, mas nunca o explicam ou exploram; muito ao contrário, eles imediatamente abandonam esta referência e passam a reportar-se ao "movimento" dos corpos.

Reforçando o desenvolvimento da exposição teórica nesta perspectiva, todos os exemplos, discussões e figuras são da mesma natureza: os corpos movimentam-se sempre sobre uma superfície fixa e o eventualmente mencionado "movimento relativo das superfícies" esvazia-se e perde o seu significado.

A citações que se seguem exemplificam bem o que acabamos de expor.

No livro $S_{1}$, pág. 237, na introdução do capítulo intitulado "Forças de atrito", pode-se ler: "O atrito é denominado dinâmico quando há movimento relativo entre os corpos em contato. Quando não há movimento o atrito é denominado estático."

Embora não seja especificado que o movimento relativo em causa é o de escorregamento, observe-se também que no $2^{2}$ parágrafo o "relativo" já desapareceu! O resto da exposição continua nesta mesma linha. Mais na frente, na pág. 243, a título de conclusão, os autores colocam:

"Reunindo as conclusões obtidas sobre a força de atrito entre sólidos em contato, temos:

corpo em repouso: $0 \leq f_{a t} \leq \mu_{e} N$

corpo em movimento: $f_{\text {at }}=\mu_{d} N$ "

Por outro lado, os livros que abordam o movimento de rolamento $\left(S_{1}, S_{3}, S_{6}\right.$ e $\left.S_{7}\right)$ ou fazem-no definindo um atrito de rolamento $\left(S_{6}\right.$ e $\left.S_{7}\right)$ ou através de exemplos $\left(S_{1}\right.$ e $\left.S_{3}\right)$.

Neste último caso, geralmente utilizando o exemplo da rodas de um carro, não é esclarecido ou discutido o tipo de atrito que está em causa: fala-se simplesmente na existência de um "atrito" entre as superfícies em contato ou das "forças de atrito" que são exercidas. 
Continuando com o mesmo livro $\left(\mathrm{S}_{1}\right)$, nas páginas 247-248, sob o título de "Quanto o atrito é importante", os autores discutem com bastante detalhe e figuras ilustrativas, o problema do atrito na sola dos sapatos quando se caminha e nas rodas de um carro, estudando o caso das rodas terem tração motora ou não e o que acontece quando a tração é dianteira ou traseira. Nesta detalhada discussão nunca é especificado o tipo de atrito em causa. Os autores optaram pelos termos ambíguos de "atrito" ou "forças de atrito".

Desta forma não é difícil para o leitor inferir ou concluir, conscientemente ou não, que o atrito existente quando um corpo rola é cinético, já que o corpo está em movimento, justificativa apresentada por um número importante de professores no estudo exploratório comentado anteriormente.

No caso em que o atrito de rolamento é abordado $\left(S_{6}\right.$ e $\left.S_{7}\right)$ ele é definido de forma semelhante aos livros da $8^{\text {a }}$ série, quando distinguem os tipos de atrito.

Pode-se ler na "Introdução" do livro [S, pág.156] do capítulo 3 (pp. 156-170) reservado para o estudo do "Atrito", o seguinte:

" Distinguem-se, particularmente, dois tipos de atrito:

a) Atrito de deslizamento ou de escorregamento (em itálico no original):

Quando uma superfície desliza (escorrega) sobre outra

Ex.: Uma caixa puxada por uma corda sobre uma superfície

b) Atrito de rolamento (em itálico no original):

Quando uma superfície gira (rola) sobre a outra

Ex.: A roda de um carro em contato com o solo

Na página seguinte, no item 3.3 de título "Tipos de força de atrito", lê-se:

"Há dois tipos de força de atrito: estática e dinâmica

a) Força de atrito estática (em itálico no original):

É aquela que atua quando não houver movimento. ...

b) Força de atrito dinâmica (em itálico no original):

É aquela que atua durante o movimento. Para começar o movimento, partindo do estado de repouso, é preciso que a intensidade da força motriz seja superior à intensidade da força de atrito de destaque ${ }^{9}$.

Logo em seguida, tem uma figura de duas pessoas empurrando um carro, com a seguinte legenda: " $F>$ fat $_{\text {destaque }} \therefore$ há movimento."

Abaixo desta legenda, o autor continua:

"Uma vez iniciado o movimento, a força de atrito estático deixa de existir, passando a atuar a força de atrito dinâmica..."

Verifica-se que segundo as definições dos autores, quando um corpo rola existe um atrito de rolamento, única característica atrelada a este tipo de atrito e, ao mesmo tempo, dando o exemplo do carro que é empurrado por duas pessoas, os autores inscrevem este exemplo no item de "Forca de atrito dinâmica", com a legenda e o texto acima citados.

\footnotetext{
${ }^{9}$ Força de atrito de destaque é definida no original como sendo o valor máximo da força de atrito estática.
} 
Como entender ou o que entender?

No livro [ $\left.\mathrm{S}_{6}\right]$, é também mencionado que o atrito pode ser de rolamento; são dados exemplos, através de figuras, de corpos que rolam como aquele em que "uma bola está rolando sendo direcionada (empurrada) por uma pessoa", mas como nos outros livros que abordam o rolamento, reina a ausência de informações ou a ambigüidade sobre este tipo de atrito.

\section{Síntese comparativa dos resultados}

A fim de possibilitar uma visão mais global dos resultados obtidos na análise desenvolvida nos dois níveis de ensino abordados e na perspectiva de responder mais objetivamente às questões de estudo propostas (do ponto de vista da Física), sintetizaremos o conjunto dos resultados no quadro comparativo que se segue:

\section{Quadro comparativo dos resultados gerais obtidos na análise dos livros didáticos nos} dois níveis de ensino abordados no estudo

\begin{tabular}{|c|c|c|c|}
\hline $\begin{array}{l}\text { Tipos de } \\
\text { Atrito }\end{array}$ & $\begin{array}{l}\text { Questões de estudo: } \\
\text { Ponto de vista da Física }\end{array}$ & $\begin{array}{l}\text { Livros da } 8^{\mathrm{a}} \text { série do } \\
\text { Ensino Fundamental } \\
\qquad \mathrm{N}=7\end{array}$ & $\begin{array}{c}\text { Livros do } \\
\text { Ensino Médio } \\
\text { N=8 }\end{array}$ \\
\hline \multirow{3}{*}{$\begin{array}{c}\text { Atrito } \\
\text { Estático } \\
\text { e } \\
\text { Atrito } \\
\text { Cinético }\end{array}$} & $\begin{array}{c}\text { Os livros fazem distinção } \\
\text { entre atrito estático e } \\
\text { cinético? }\end{array}$ & Em 1livro & Em todos \\
\hline & $\begin{array}{c}\text { Como estes fenômenos são } \\
\text { distinguidos/definidos? }\end{array}$ & \multicolumn{2}{|c|}{$\begin{array}{l}\text { Pelo estado de movimento (atrito cinético) ou } \\
\text { de repouso (atrito estático) no referencial dado }\end{array}$} \\
\hline & $\begin{array}{l}\text { A que movimentos são eles } \\
\text { associados? }\end{array}$ & \multicolumn{2}{|c|}{$\begin{array}{l}\text { Ao movimento de translação (atrito cinético) } \\
\text { ou repouso (atrito estático) não relativos }\end{array}$} \\
\hline \multirow{4}{*}{$\begin{array}{c}\text { Atrito } \\
\text { de } \\
\text { Rolamento }\end{array}$} & $\begin{array}{l}\text { O atrito de rolamento é } \\
\text { abordado nos livros? }\end{array}$ & $\mathrm{N}=4$ & $\mathrm{~N}=2$ \\
\hline & Como ele é definido? & \multicolumn{2}{|c|}{$\begin{array}{c}\text { "Definição": o atrito de rolamento aparece } \\
\text { quando um corpo rola ou gira }\end{array}$} \\
\hline & $\begin{array}{l}\text { A que tipo de movimentos é } \\
\text { ele associado? }\end{array}$ & \multicolumn{2}{|c|}{$\begin{array}{l}\text { Ao movimento de rolamento em geral (sem } \\
\text { especificar se é com ou sem deslizamento) }\end{array}$} \\
\hline & $\begin{array}{l}\text { Como ele se integra com o } \\
\text { atrito estático e cinético? }\end{array}$ & \multicolumn{2}{|c|}{$\begin{array}{l}\text { Associação do atrito estático e cinético à } \\
\text { translação e o de rolamento à rotação }\end{array}$} \\
\hline
\end{tabular}

Em resumo, as análises desenvolvidas indicam que os autores dos livros de $8^{\mathrm{a}}$ série do Ensino Fundamental, onde existe o primeiro contato formal com o fenômeno do atrito sólido, ao optarem pela supressão ou generalização das informações, apesar de uma certa diversidade entre os autores na exposição do conteúdo, não ajudam certamente o leitor a construir uma visão inequívoca e sem ambigüidades sobre os tipos de atrito e os movimentos aos quais estes são associados: o atrito estático está sistematicamente ausente do discurso e quando não está, ele é associado somente ao repouso (não relativo) dos corpos, o atrito cinético é associado ao "movimento" destes e quando o movimento de rolamento é abordado, ele é associado 
ambiguamente a um atrito de rolamento porque "os corpos rolam" ou simplesmente a um "atrito"sem se especificar de que tipo de atrito se trata.

Quando se passa para os livros do Ensino Médio, a diversidade com que o conteúdo é exposto desaparece, os atritos estático e cinético são clara e explicitamente definidos e, também, clara e explicitamente associados, respectivamente, aos estados de repouso (não relativo) e "movimento" dos corpos, tal como nos livros da 8 a série.

A atribuição da presença de um atrito de rolamento para os corpos que rolam aparece mais raramente, mas quando aparece também é definido inadequadamente como nos livros de $8^{\text {a }}$ série ou, tal como nestes livros, o tipo de atrito existente no movimento de rolamento não é definido, sendo, da mesma forma, ambiguamente denominado "atrito".

Entretanto, observou-se nos livros do Ensino Médio comparativamente àqueles do Ensino Fundamental, um cuidado bastante maior nas formas de expressão do conteúdo, no que se refere ao que nós chamamos de "confusão" entre o fenômeno do atrito e a força de atrito. Este tipo de "confusão" é praticamente ausente nos livros do Ensino Médio.

\section{Conclusão}

Os resultados indicam que o modelo utilizado nos livros de ambos os níveis de ensino para introduzir o conceito de atrito/forças de atrito é basicamente o mesmo, total e unicamente apoiado em exemplos onde os corpos sempre se deslocam em relação a uma superfície fixa, onde a relação entre 0 atrito e os movimentos relativos de escorregamento das superfícies umas em relação às outras é ignorada ou esvaziada, contribuindo fortemente para uma formação conceitual inadequada e redutora do fenômeno do atrito sólido seco.

Desta forma, os resultados apontam diferenças qualitativas pouco expressivas ou quase inexistentes no conteúdo estudado dos livros do Ensino Médio, entre si, e naqueles do 8ª série do Ensino Fundamental, assim como mostrou-se pouco expressiva a evolução qualitativa dos livros do Ensino Médio em relação àqueles da $8^{a}$ série do Ensino Fundamental, esta evolução ficando muito mais por conta da quantidade e organização mais sistematizada da informação do que na sua qualidade, salvo no que diz respeito às formas de expressão do conteúdo.

Por outro lado, o estudo indica que os resultados obtidos com os professores, fonte direta da origem deste trabalho, são perfeitamente compatíveis e coerentes com os resultados obtidos das análises dos livros aqui desenvolvidas. Isto está de acordo com os estudos que indicam que os professores usam quase que apenas o próprio livro didático como recurso para o preparo das suas aulas, e ainda de forma pouco crítica. Confirmando também a importância do livro didático, deve-se ter em conta que o seu papel deveria ser, no mínimo, o de não reforçar o senso comum ou não facilitar a construção de modos de raciocínio nele baseados.

Neste sentido, o contexto geral do nosso trabalho e de todos os outros desta linha de investigação apontam para a importância e necessidade da construção de textos didáticos que, em primeira instância, levem seriamente em consideração as grandes tendências do conhecimento de senso comum de modo a facilitar o processo de construção de um conhecimento mais próximo do científico. 
Em particular, os resultados deste trabalho colocaram em evidência alguns pontos "críticos" que nos parecem essenciais observar no estudo do atrito sólido seco e que justificam as seguintes recomendações ou sugestões:

- Definir que o que intervém no estudo do atrito, é o movimento de escorregamento relativo das zonas de contato dos sólidos concernentes (velocidade relativa de escorregamento), umas em relação às outras, ou a ausência deste movimento e não os "movimentos" dos sólidos no referencial dado.

- Reconhecer (identificar) entre várias situações físicas onde os sólidos deslocam-se num dado referencial, aquelas para as quais a velocidade relativa de escorregamento no contato é nula; problematizar, pois, que existem situações de "movimento" para as quais esta velocidade é nula, tanto no caso da translação dos objetos, como no caso da rotação, constituindo-se este tipo de estudo numa boa oportunidade de mostrar a importância e a necessidade de se definirem as grandezas físicas em referenciais.

- Supondo os sólidos indeformáveis, distinguir claramente os dois tipos de atrito sólido seco, o atrito de não deslizamento (estático) e o atrito de deslizamento (cinético ou dinâmico), associando estes fenômenos a situações para as quais a velocidade relativa de escorregamento no contato é, respectivamente, nula e não nula; problematizar, pois, que o atrito estático nem sempre está associado a todas as situações de repouso num dado referencial e nem todas as situações de movimento estão associadas ao atrito cinético.

- Num estudo limitado à suposição de que os sólidos são absolutamente rígidos (sólidos indeformáveis) e perfeitamente geométricos, a definição de um atrito de rolamento não é fisicamente cabível. Ou elimina-se esta suposição e define-se claramente $o$ atrito de rolamento e as condições em que ele aparece (deformação dos sólidos em contato), o que, como já mostramos, não é um assunto trivial, ou ignora-se a existência deste tipo de atrito, o que é perfeitamente adequado nos limites dos conteúdos dos níveis do Ensino Fundamental e Médio.

- Rigor, sem concessões, nas expressões utilizadas quando se fala em forças de atrito e no fenômeno do atrito, conforme já discutido: as forças de atrito, como quaisquer outras forças que obedecem às leis de Newton, são exercidas por algum agente sobre o objeto em estudo (elas não existem, pois, entre os objetos), e o fenômeno do atrito, evento que ocorre quando as superfícies em contato são solicitadas por algum agente externo, não é portanto uma força e nem pode ser tratado como tal, pois por elas (forças de atrito) é modelado.

Este tipo de recomendações supõe romper com o modelo de abordagem do fenômeno do atrito habitualmente utilizado pela grande maioria dos livros didáticos nos diversos níveis de ensino, mesmo no Ensino Superior (Caldas \& Saltiel, 1999b), mas que este estudo juntamente com diversos outros anteriormente citados apontam como sendo um modelo que, além de não levar em conta o conhecimento de senso comum do aprendiz, mostra-se inadequado e redutor do ponto de vista científico. 


\section{Agradecimentos}

Os nossos sinceros agradecimentos ao professor Ennio Candotti pelas inúmeras e frutíferas discussões que tanto têm contribuído para o desenvolvimento do nosso trabalho.

\section{Anexos}

Referências Bibliográficas dos Livros Analisados

- $8^{\text {a }}$ Série do Ensino Fundamental

[L $\mathrm{L}_{1}$ ] MARCONDES A. C., SARIEGO J. C.,1996. Química e Física: $8^{a}$ série. $2^{\mathrm{a}}$ ed., Scipione, S. Paulo.

[L르 GOUDAK D., MARTINS E., 1996. Natureza e Vida: 8a série. FTD S.A., S. Paulo.

$\left[L_{3}\right]$ LOPES S., MACHADO A.,1996. A Matéria e a Vida, $8^{a}$ série. Atual, S. Paulo.

[L4] BARROS C., PAULINO W. R., 1998. Física e Química, $8^{a}$ série. 53aa ed., Ática, S. Paulo.

[L5] CRUZ D., 1998. Ciência e Educação Ambiental - Química e Física, $8^{a}$ série. 23 $3^{\mathrm{a}}$ ed., Ática, S. Paulo.

[L6] JUNIOR C. S., SASSON S., SANCHES P. S. B.,1998. Entendendo a Natureza a Matéria e a energia: $8^{a}$ série. $15^{\text {a }}$ ed., Saraiva, S. Paulo.

[L7] SILVA P. M., FONTINHA S. R.,1997. Química e Física. A matéria e a energia em transformação. Ciências. $8^{\underline{a}}$ série. Nacional, S. Paulo.

$\left[\mathrm{L}_{8}\right]$ SILVA P. M., FONTINHA S. R., 1997. Química e Física. Ambiente, componentes e interações: ciências. $8^{a}$ série. Nacional, S. Paulo.

[Lo] ASSUNÇÃO M. A. Ciências. A Caminho do Futuro. Vigília.

- Ensino Médio

[S ${ }_{1}$ ] RAMALHO F., NicOlaU G. F., TOledo P. A., 1995. Os Fundamentos da Física. Mecânica - Volume 1. $6^{\text {a }}$ edição, Moderna, São Paulo.

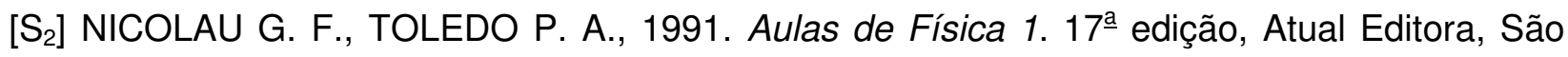
Paulo.

[S $\left.{ }_{3}\right]$ MÁXIMO A., ALVARENGA B., 1992. Curso de Física - Volume I . $3^{\text {a }}$ edição, Harbra, S. Paulo.

[S $\left.{ }_{4}\right]$ MÁXIMO A., ALVARENGA B., 1997. Física - Volume Único - Curso Completo. Scipione, São Paulo.

[S ${ }_{5}$ ] PARANÁ D. N., 1993. Física - Volume 1. 2ª̣ edição, Ática, S. Paulo.

[S $\mathrm{S}_{6}$ ] OLIVEIRA P. C.,1993. Princípios da Física. Lê, Belo Horizonte.

$\left[\mathrm{S}_{7}\right]$ BONJORNO et ali, 1985. Física - Volume 1. FTD S. A.., S. Paulo.

[S ${ }_{8}$ CURSO DO "OBJETIVO", 1999. Resumo: Dinâmica; Força de atrito. Apostila do curso, Vitória. 


\section{Referências Bibliográficas}

AGUIRRE DE CÁRCER I., 1993. Dificultades en la comprensión de las explicaciones de los libros de texto de física. Enseñanza de las Ciencias. 1(2): 92-98.

BESSON U., 1997. Le frottement solide sec de glissement. Relatório de tutorado, DEA Laboratoire de Didactique des Sciences Physiques. Université Paris 7, Paris, França.

BRINCONES I., OTERO J., 1994. Students Conceptions of the Top-Level Structure of Physics Texts. Science Education. 78 (2): 171-183.

CALDAS H., 1994. Le frottement solide sec: le frottement de glissement et de non-glissement. Etude des difficultés des étudiants et analyse de manuels. Université Paris 7, Paris, França. (Tese, Doutorado)

CALDAS H., SALTIEL E., 1995. Le frottement cinétique: analyse des raisonnements des étudiants. Didaskalia: Recherches sur la communication et l'apprentissage des sciences et des techniques. 6: 55-71.

CALDAS H., 1999 (colaboração de E. Saltiel). Atrito: o que diz a Física, o que os alunos pensam e o que os livros explicam. Edufes, Vitória, ES, Brasil.

CALDAS H., SALTIEL E., 1999a. Sentido das forças de atrito e movimento - I. Revista Brasileira de Ensino de Física. 21 (3): 359-365.

CALDAS H., SALTIEL E., 1999b. Sentido das forças de atrito e movimento - II. Uma análise dos livros utilizados no ensino superior brasileiro. Revista Brasileira de Ensino de Física. 21 (4): 542-549.

CALDAS H., SALTIEL E., 2000. Le frottement statique: analyse des raisonnements des étudiants. Didaskalia: Recherches sur la communication et l'apprentissage des sciences et des techniques. 17: in press.

CALDAS H., Magalhães m. e. rolamento sem escorregamento: atrito estatico ou atrito de rolamento? caderno catarinense de ensino de fisica. (submetido para publicação, 1999).

CUNHA A. L., CALDAS H., 2000. Sentido das forças de atrito e os livros da $8^{a}$ série. Caderno Catarinense de Ensino de Física. 17 (1): in press.

ISLAS S. M., GURIDI V. M., 1999. El quehacer científico versus el quehacer áulico. Buscando rasgos del quehacer científico en libros de texto. Enseñanza de las Ciencias. 17(2): 281290.

MENINGAUX J.,1986. La schématisation des interactions en classe de troisième. BUP: Bulletin de I'Union des Physiciens. 683: 761-778.

SALTIEL E., 1978. Concepts cinématiques et raisonnements naturels: étude et compréhension des changements de référentiels par les étudiants en sciences. Université Paris 7, Paris, França (Tese, Doutorado).

SALTIEL E., MALGRANGE J. L., 1979. Les raisonnements naturels en cinématique élémentaire. BUP: Bulletin de I'Union des Physiciens. 616:1325-1355.

SHAW DONALD E., 1979. Frictional force on rolling objets. American Journal of Physics. 47 (10): 887-888.

VIENNOT L., 1979. Le raisonnement spontané en dynamique élémentaire. Hermann, Paris.

VIENNOT L., 1996. Raisonner en Physique: la part du sens commun. De Boeck \& Larcier, Paris, Bruxelles. 
WEHRBEIN WILLIAM M., 1992. Frictional forces on a inclined plane. American Journal of Physics. 60 (1): 57-58. 